\title{
Musings ON THE Engagement OF THE NeOPHYTE WITH THE ESTABLISHED ARCHIVE
}

\author{
Fredyl B. Hernandez \\ De La Salle - College of Saint Benilde, Manila, Philippines, \\ contact: fredyl.hernandez@ benilde.edu.ph
}

\begin{abstract}
Music Production of De La Salle - College of Saint Benilde is a program first of its kind in the Philippines. Oriented to trail-blaze for 21st century Filipino musicians, the Music Production program is to be found not in a conservatory, but in a School of Design and Arts. As such, the program ensures responsiveness to the needs of the Creative Industries. With the government's Long-term Development Plan, wherein culture and the arts are seen as key social and economic capitals, something is to look forward for people who innately possess a certain degree of musicality whether in traditional, folk, popular, indie or in other formats. The program, to a certain extent, makes its own contribution in realizing this governmental thrust.

Situated in an amalgamation of cultural expressions as a result of historical determinations, sound and music culture in the Philippines feature a fusion of genres which also naturally results to distinct forms in the fusion and weaving processes. Recognizing this rich context, the program offers a wide variety of training to its students, and sensitive to the needs of the industry, outputs are always made relevant to the demands of the market and the society at large.

The capstone projects of the students as well as their other outputs from immersions and on-the-job trainings are in need of safeguarding and proper documentation. In the program's over two decades of existence, there is no good reason to wait for these outputs to become archaic in the future, acquiring the status of becoming objects or pieces of curiosities. The archival initiative is premised on the idea that these productivities entail a wealth of contemporary musical expressions nurtured in an emerging field of formal learning and mentoring. Offhand, there is a felt necessity of tracing the development of works. At the same time, as prompted by trends, the question to be asked now: What direction must the program take in order to be truly responsive to the industry as well as to actively engage in cultivating contemporary practices of music in the Philippines and in the world?

Lastly, the archive is also a soundscape. Akin to the recording of varied sounds simultaneously present in an environment, the archive becomes an instrument of digitizing culture and pedagogy - of recording thought and learning processes of young people as well as educational approaches and methodologies in the part of the program. The initiative seeks to explore the charting of pedagogical outputs - its domiciliation and consignation, and processes involved in its retrieval and dissemination.
\end{abstract}

\section{Keywords}

Performing arts, digitizing pedagogy, project outcomes, archiving of events, Philippines

I was enticed at first by the idea of considering present-day pedagogical outputs of a musicmaking degree program as potential materials for present day archiving. The reason behind this enticement is my context of belonging to a unit of relatively young higher education institution that maintains a thrust of keen responsiveness of arts, design, and culture to market and industry. To my mind, it would be an interesting endeavour to tease out the young and his creations with the established institution of the archive. The project in mind was premised on the idea that compositions of today are possible contents of the archive in the future. What I 
imagine, therefore, is an archive that has a close conversation with the materials which are presently produced, in contrast to its reactionary role of scouting remnants such as historical documents, cultural artefacts, and audio-visual recordings from the past. I was stirred by the idea that contemporary art production belongs to the continuum of expression of communal memory and knowledge, and if we see the archive as a sort of repository of culture then it must have a dialogical relationship with the so-called new or the emergent. I envision an archive actively engaging itself with what is surfacing and developing and not simply a static body that waits for human creations to age.

It is a fact that these present-day outputs may naturally not conform to the condition of being tested by time and of embodying some distant memory which merit them to be placed in a well-guarded and maintained space for keeping. As mentioned earlier, I argue that these creations entail a contemporary way or mode of thinking and expression and that very fact suffices to be a good reason for these outputs to be placed in a repository of sorts, hopefully in a manner that is framed by an archivist, or at the very least an advocate of archival work, someone who treats the materials in relation to its use as future references. These music outputs can be treated as documents of thought and learning processes in pedagogical point of view. These are also concrete manifestations of learning approaches, methodology, and philosophy of the program and of the entire educational institution. They mirror not only the interests and concerns of our young people but as well as the educational standpoint of the academic institution. I envision the project as a sort of an archive of recent memories, which are articulated in contemporary musical compositions.

In starting however, to concretize my research in safeguarding pedagogical outputs, it seems to me that such kind of endeavour boils down to the concept of having a reliable structure of administrative safekeeping, an aspect that is naturally expected to be present in good academic program management. I realized that the movement of such inquiry necessitates a direction towards the creation of a sound model of institutional practice of systematic upkeep of artistic compositions of students. I decided not to pursue that direction for the reason that the archive and the archival work will be placed in the background. Instead, I chose to simply focus on some nuances entailed in the processes of establishing a more convivial relationship between new interests and perspectives, emergent orientations, including new users, with the established and time-honoured archive.

I belong to a cluster of academic programs ${ }^{1}$ that carves a niche in the merging of professional art practice, arts and cultural management, and creative industries. I am part of a service department that maintains a thrust of interdisciplinary inquiry on arts and cultural studies. We have a Music Production program in our cluster which is relatively a young degree of almost two decades of existence. It's the first of its kind in the Philippines being a program that is oriented to trail-blaze for the $21^{\text {st }}$ century Filipino musicians, or to use a more inclusive term, music practitioners. The needs, directions, and developments in the creative or cultural industries are important considerations in the program's design. For instance, outputs in the program are always making sure to be relevant to the demands of the market and the society at large. The program "... reflects the diversity of musical experience - mixing sounds, composing songs, producing musical performances - to ensure that ... learning remains relevant in the music business." 2 Also, one can say that the present global trend of how arts and culture are heavily boosted as key social and economic capitals that can bring long-term

\footnotetext{
1 Our academic cluster's name is Benilde's Arts and Culture Cluster (BACC) of the School of Design and Arts, De La Salle - College of Saint Benilde, in Malate, Manila City, Philippines.

2 Https://www.benilde.edu.ph/courses/tracks/ad/music-production.html, last accessed 7 October, 2019.
} 
development of third world countries, ${ }^{3}$ is somewhat resonated in the opportunities and trajectories that the program provides its students. With all these at the background, the program can be described as undoubtedly situated outside the usual concerns of the senior and established archive for the reason that its gaze is directed to what it's happening in the now rather than to what had happened in the past.

On the contrary, because an academic program intends to give a well-rounded education and skills development, to some extent, the students are expected to become natural users of the archive. Familiarization of the past, including those sources of influences from different cultures surely gives a good grounding to one's practice. In the Philippines, just like any nation-state which was once subjugated in the colonial structure, the spectrum of sound and music culture features a fusion of genres - Austronesian, Hispanic-European, AmericanWestern, and indigenized. Recognizing this richness of the amalgamation and hybridity in the field as a result of historical determinations, the program offers a wide variety of training to its students in order to provide them with both local and global perspectives on how music developed as a field in the country. Music cultures, in both traditional and modern expressions, entail "unique musical systems with its own vocabulary" (Mirano, 1997: 145) which definitely predicates the appreciation and valuation of music as phenomena that simultaneously and uniquely taking place in various corners of the globe. Likewise, just like any other art form, music is also seen as a mediator in social interactions. In cultural studies, it can be perceived as a means that offers ways of "negotiating identity and (of) locating and relocating oneself in society" (Sirek, 2017: 55). With this, we see points of intersection between sound and music archives, and the complex undertaking of marking one's identity through artistic compositions. All music composers including student-artists who explore and create in the present join in that process of continuously creating, cultivating, and navigating cultures which entail both affirming and contesting identities. In an industry-related degree program, a facet of construction and reconstructions of identity is always being charted. Hence, the archive remains to be a helpful reference in obtaining a good grasp of the past which in turn will inform the direction of identity discourse through musical compositions.

The program is one of the thriving degree offerings of the school. It attracts a lot of young people who probably considered music as a hobby in high school perhaps as a member of a band, a choir, or a singing group, and eventually decided to pursue music in college. At present, there is an influx of students in the program which can still be considered as part of the first waves of graduates of the K-12 educational reform instituted seven years ago. The Philippines belongs to the last two countries in Southeast Asia that implemented the K-12 educational system. In this surge of enrollees, it is interesting to note that only a handful took Arts and Design track in their senior high school, an understandable thing as there are very limited number of senior high schools throughout the country which offer arts and design more so with a specialization in Music. ${ }^{4}$ This is the general background of the students who are joining the program. Their first terms in the program are crucial months of orienting them to the field that they are entering. Later, in their final year of stay, a certain sense of privileging to experimentation of contemporary forms are eventually given to students. They have the liberty to pursue the type of music which they would like to explore and pursue

\footnotetext{
3 The Philippine Development Plan 2017-2022 attest to this thrust. Subsector Outcome 3 under Chapter 7 (Promoting Philippine Culture and Values) aims to "Boost the development of Filipino creativity as a tool for cohesion and impetus for a culture-based industry and creative economy." National Economic Development Authority. Philippine Development Plan 2017-2022: 101.

4 For example, I handled a block section in Art History class composed of freshmen Music Production majors, during the $1^{\text {st }}$ term of the school year 2019-2020. Out of 30 students, only four attended the arts and design track in senior high school.
} 
under the supervision of their faculty advisers. A general review of the students' outputs in almost two decades of the program shows that music technology heavily influenced the compositions. It generally bears the urban and the popular mark. ${ }^{5}$

My guideposts in this preliminary study involves a reflection on the following questions: How does a relatively young and contemporary music program makes sense of sound archives? What are the entry points of the program in the archive not only as a user but as a participant and contributor in expanding its discourses? What areas of productive engagement can an admittedly market or industry-driven program engage with the archive as an institution that places a premium on preservation and transmission of knowledge from the past? An important point to consider in these questions is the context of my musings that is not just limited to sound archival but to the archive in general and on how the public is presently engaging with it.

My first encounter with the archive was during my last year in high school. I remember that part of my thesis recital work at the Philippine High School of Arts, the first specialized school on arts-focused education in the country, was to obtain a sound recording of a Peking Opera excerpt at the College of Music, University of the Philippines Diliman. After going through the list of Chinese opera audio recordings, I was able to locate what I was looking for and record it using a blank cassette tape. The internet was not yet widely used at that time. It was during those years in which the CD ROM encyclopedia was considered as the edgy research tool of an ordinary student researcher. I handed over the recorded material I obtained from the archive to the head of our school's music program who assisted us in the live sound scoring of the production recital. We were fully aware at that time that it was not in our intention to create an authentic Peking Opera because we will never arrive to such kind of performance. Rather, our intent was born out of a noble desire to include cultural performances in Asia in our theater repertoire and not just be limited with the materials from European playwrights who are usually the ones to be found in the canon of drama.

This personal experience of the archive illustrates that action of retrieval of a record of an age-old tradition, a material from a totally foreign culture, for the purposes of familiarization as well as utilization of it as a jumping board for performance creation. Such experience demonstrates a picture of the practical usefulness of the archive to ordinary individuals who have very limited knowledge, to the novice, the neophyte, or to the uninformed who come from outside the ambit of arts, culture, or the very specialized field of sound archiving. After all, the archive maintains an attitude of openness to all, a willingness to accommodate anyone who may be in need of whatever it possesses. The rationale behind its creation is concretely realized when the public, experts and lay people alike, enter it and sift through its contents and eventually produce something out of what they have significantly gathered from the archive.

The guidepost questions I mentioned earlier are born out from my contemplations as regards the workshop's thrust on safeguarding strategies for sound archiving as well as informed by the arts and cultural program in my home base academic institution. Beyond those contexts, I also wish to tease out the general situation of archiving in the Philippines and on how the ordinary person or the novice can navigate and make sense of what our archives in the country offer. A closer scrutiny on the situation and practice in Philippine archiving reveals a situation that is very far from the level of sophistication of discourses and practices found among institutions from well-off nation-states. We have a government unit under the Office of the President, the National Archives of the Philippines, which keeps historical documents

\footnotetext{
5 Interview with Agnes Asunta Manalo, former Program Chair of Music Production, 08 July 2019.
} 
mostly from Spanish colonial period. In May 2018, the administrative building of the national archives was hit by fire. Luckily, the principal collection was not destroyed as it was placed in another location in keeping with established institutional practice. Despite the many limitations it faces, the National Archive is continuously working hard on the digitization of its collection. As if with some sort of foreshadowing, the Faculty Center of the University of the Philippines Diliman, the headquarters of the professors of the College of Arts and Letters, and the College of Social Sciences and Philosophy, was totally destroyed by fire in 2016. Many lamented the great academic loss of volumes of research outputs as well as documentation and actual creative works of professors and students alike. It was truly an illfated event particularly to people who value the keeping of artistic and academic productivities. On the contrary, it paved the way for the university to seriously undertake a project on digital Humanities which involves the recording of performances including musical traditions from various cultural communities in the country.

In 2014 and 2015, I had a chance of cultural immersion to two remote villages in the town of Alimodian, Iloilo in the Western Visayan Region. I did some initial video recording of an indigenized Catholic ritual called Sukat or Bungkag Lalaw that marks the mourning period of a bereaved family. Sukat connotes a year that has already passed. Usually, the ritual takes place a year after the death of the family member but, in some instances, it is extended to two or three years depending on the capacity of the family to hold a feast. Bungkag Lalaw means end of mourning. ${ }^{6}$ In one village located on top of mountain ranges some 25 -kilometer away from the town proper in the lowland, the ritual is officiated by a lead woman cantor who performs a pseudo-priestly role in the ceremony, like in officiating the act of blessing the altar and the house with water, and the chanting of a prayer text which is clearly recognizable as something based from the Latin language. A simple band composed of a guitar, banjo, trumpet, and bass drum accompanied the singing. The ritual was strongly marked by visuals such as a makeshift small coffin at the center surrounded by candles. The altar was draped with a black piece of cloth with a crucifix as well as other statues of saints, and food offering. The black cloth was removed towards the end part of the ceremony revealing a red cloth beneath it wherein once exposed marks the formal end of the family's mourning. A feast followed after the ceremony, and everyone in the community took part in it.

In the previous decades, a good number of anthropologists, particularly dance and music researchers have focused their studies on sound and music cultures of various communities in the Philippines. Seminal works were created in the 80s and in the following decades, but a lot of work has still to be done. There are knowledge systems that are already on the brink of extinction because they are no longer patronized even within the local community. Also, there are forms that are inherently ephemeral such as rituals and prayers that are being chanted but never written nor recorded. There are plenty of artistic and cultural expressions which need to be studied in a more nuanced way and be brought to the attention of individuals familiar to archival preservation. In many instances, written outputs of the researches were produced, but the materials gathered from the community, such as sound recordings were never properly kept.

There are two very important givens about the archive that I would like to revisit at this point. First, the archive bears a notion of age. As regards to what it holds, the contents of the archive

\footnotetext{
6 Online interview with Evelyn Amor, key informant from Mambawi, Alimodian, Iloilo, 08 March 2020. The house where I stayed during my immersion was just next to her residence. A distant relative of her family held a Sukat or Bungkag Lalaw during my stay in their village. It was my first time to witness the ceremony and listen to the chanting. The following year, I witnessed another Sukat ceremony in the upland village of Tabug, in a cluster of villages in the mountains called by the locals as Seven Cities.
} 
implicate no simple number of years of presence but decades even centuries of existence. Whatever the archive holds must simply have gone through a lot. A sense of being able to endure the tests of time and of withstanding changes on various levels can easily be intuited even before going through what the archive holds. Second, the archive speaks of meaning. A thing is being archived because someone or a community places meaning to it, including the archivist. Akin to a curator who works on choices, whose selection of objects and pieces to be included in a display is informed by various considerations, the archivist makes sense of the objects included in the archive through a system of signification. To be placed in the archive means for the object to be charged with meaning. A thing persists inside the archive because its placement has been assigned with a certain relevance, and that assignment of value is recognized by systems supporting the archive.

There is a dimension to it as "selective shaping of remembered past". (Craig, 2004: 9). Jacques Derrida calls these processes as domiciliation and consignation. (Derrida, 1995: 10). He describes that objects "... which are not always discursive ..." are mediated by a "legitimate hermeneutic authority." In the context of maintaining a collection of objects from the past, that authority is named as the archivist. The processes he called "functions of unification, of identification, of classification..." are referenced to "the power of consignation" (Derrida, 1995: 10), or the authority to assign and formalize meaning. Of course, we know that Derrida's investigation is situated in the understanding of memory as repository space, in the field of psychoanalysis, but his idea of authority and truth is instructive in understanding the nature of the work of the archivist. As a person of influence and power, he has an important role in providing direction for the archive's collection including how it will be accessed and enriched by the public.

Natural and man-made calamities and other unfortunate events, such as fire which destroyed the research collection of some UP Diliman faculty members, as well as placed in danger the administrative records of the National Archives of the Philippines, necessitate a modern approach in archival. In our present state of advancement, it is but a natural move to take recourse to technology in preserving documents and records from the past. However, Barbara Craig poses a cautioning in this transfer of recording format for the reason that the fast-paced updating of what one holds eventually leads to very rapid even hyper systems of appraisal. In other words, because materials become readily available, the way of deciding what needs to be kept and discarded becomes a hasty process as well. The more we are attached to the electronics, such as the soft copy of documents and recordings, "the greater will be the urgency to appraise. Rather than allowing us to order and keep everything, digital records are notoriously fragile. (Craig, 2004: 10). Her statement is based on the trend of how documents are evaluated whether to be kept and be made available in the archive due to this fast-paced availability of materials. In the Philippines, the pressing challenge for the time being remains to be the same: transfer the format of recordings from analog to digital. We are not yet in a situation wherein the collection is already saturated by the digital files. For now, digital archives are not yet distressed by the volume of works that it needs to maintain. Craig's reflection is a forewarning of what may eventually come after fulfilling the present clamour of making things digital.

As an archive-user, researcher-scholar on arts and cultural studies, and an advocate of an expanding reach and utilization of the archive, I would like to go back to the envisioned state of engagement of the young and emerging with the established and time-honoured archive as the main premise of this study. Again, the ideas of Derrida are useful in this endeavour in terms of how the archive's processes of reflexivity entail a dimension of listening to its users. He said that "democratization involves the participation in and the access to the archive, its constitution, and its interpretation." Perhaps a concrete elaboration of these ideas, particularly 
its implications in contemporary mode of archiving is to be found in the observations of Clifford Lynch in his studies on the digital. He describes that this technology characterized by electronic tools, systems, devices, and resources, comes an apparent absence of natural communities which used to surround traditional cultural heritage materials deposited in the archive. Whatever that is placed in the digital becomes available to anyone at any place and at any time.

The reach even extends to "very strange and exotic places that you wouldn't have imagined, and sometimes (users) make extraordinarily creative or unpredicted uses of that material. Lynch proceeded with a general caution that "perhaps we should avoid over-emphasizing preconceived notions about user communities when creating digital collections."7 This does not definitely mean that we should stop understanding the emerging users of the archive but it is rather a challenge to expand our imaginations regarding these users as well as the end goal of the utilization of materials obtained from the archive. The more we engage these new set of users, these neophytes, in the direction of the archive, the more that a reflective attitude is formed. And reflexivity indicates life. It suggests an avoidance of the notion of the archive as an archaic institution and a stagnant space.

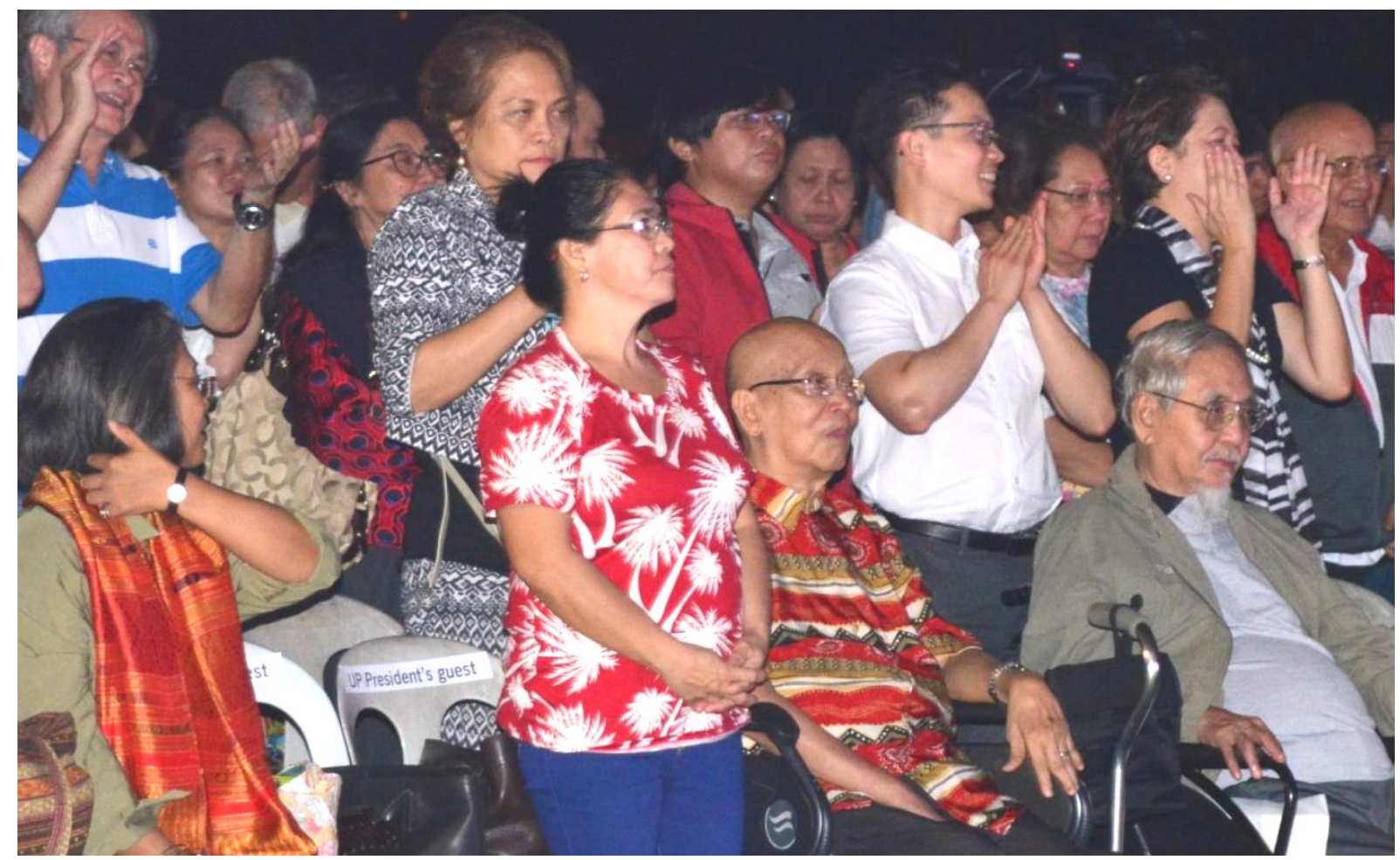

FIGURE 1: Current audiences of open air performances at the University of the Philippines Diliman (Photograph by courtesy of https://upd.edu.ph/celebrating-the-seasons-music/ last accessed 30 May, 2020).

\footnotetext{
7 The work of Clifford Lynch was mentioned in David Thomas, Simon Fowler, et al, 2017: 70.
} 


\section{REFERENCES}

Amor, Evelyn. 2020. Online interview with the author. Mambawi, Alimodian, Iloilo, on 8 March.

Asunta Manalo, Agnes. 2019. Interview with the author on 08 July.

Craig, Barbara. 2004. Archival Appraisal, Theory and Practice. München: De Gruyther.

Derrida, Jacques. 1995. Archive Fever: A Freudian Impression (transl. by Eric Prenowitz). Diacritics, 25 (2): 9-63.

Mirano, Elena R. 1997. Sound in Music Culture. Art and Society. Edited by Patrick D. Flores. Quezon City: University of the Philippines Diliman, p.145.

Music Production Program. https://www.benilde.edu.ph/courses/tracks/ad/music-production.html, last accessed 07 October 2019.

National Economic and Development Authority. 2017. The Philippine Development Plan 2017-2022, abridged version. Pasig City: www.neda.gov.ph. Last accessed 14 May, 2020.

Sirek, Danielle. 2017. Our culture is who we are! "Rescuing" Grenadian Identity through Musicking and Music Education. International Journal of Music Education. 36 (3): 47-57.

Thomas, David, Simon Fowler, et al. 2017. The Silence of the Archive. London: Facet Publishing. 